\title{
Suspension for Use in Drinking Water Dosage Form
}

National Cancer Institute

\section{Source}

National Cancer Institute. Suspension for Use in Drinking Water Dosage Form. NCI

Thesaurus. Code C149972.

Liquid preparation for veterinary use consisting of a suspension intended for administration by incorporation into the animal drinking water. If direct oral administration to individual animals is also authorized, the method of administration, including any necessary dilution, is clearly described in the product information. 